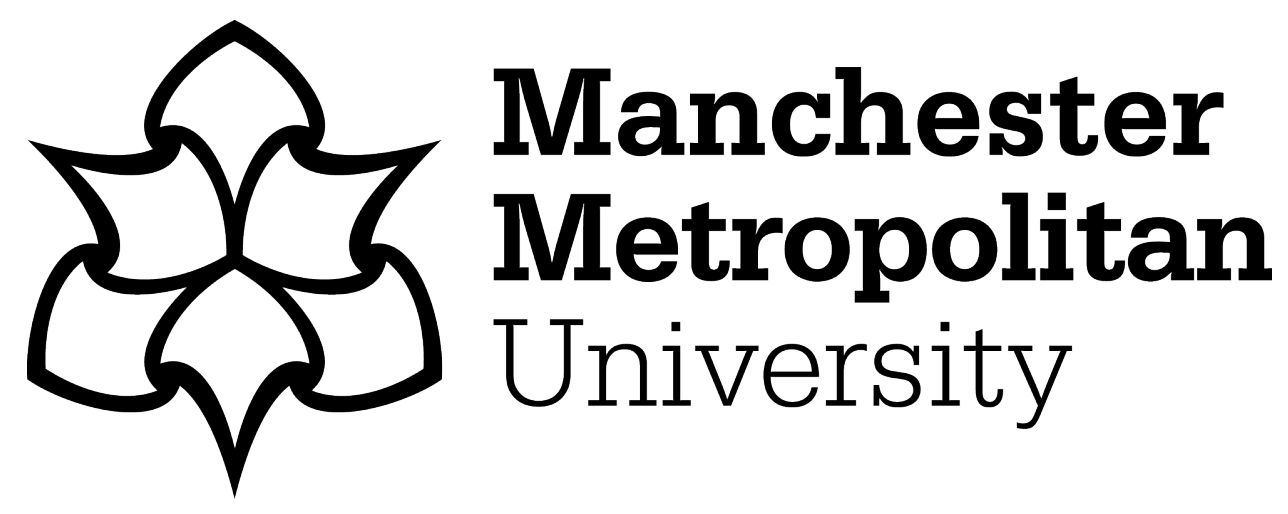

Baptista, CMSG, Cóias, JMA, Oliveira, ACM, Oliveira, NMC, Rocha, JMS, Dempsey, MJ ORCID logoORCID: https://orcid.org/0000-0002-0794-4667, Lannigan, KC and Benson, PS (2006) Natural immobilisation of microorganisms for continuous ethanol production. Enzyme and Microbial Technology, 40 (1). pp. 127-131. ISSN 0141-0229

Downloaded from: https: //e-space.mmu.ac.uk/13330/

Version: Accepted Version

Publisher: Elsevier

DOI: https://doi.org/10.1016/j.enzmictec.2005.12.025

Usage rights: Creative Commons: Attribution-Noncommercial-No Derivative Works 4.0

Please cite the published version 


\title{
Natural Immobilisation of Microorganisms for Continuous Ethanol Production
}

\author{
C.M.S.G. Baptista ${ }^{1}$, J.M.A. Cóias ${ }^{1}$, A. C. M. Oliveira ${ }^{1}$, N.M.C. Oliveira ${ }^{1}$, J.M.S. Rocha ${ }^{1}$,
}

M.J. Dempsey ${ }^{*}$, K.C. Lannigan ${ }^{2}$ and P.S. Benson ${ }^{2}$

${ }^{1}$ Department of Chemical Engineering, University of Coimbra, Pólo II, Pinhal de Marrocos, 3030-290 Coimbra, Portugal

${ }^{2}$ Department of Biological Sciences, Manchester Metropolitan University, Chester Street, Manchester, M1 5GD, UK

\section{Abstract}

Using a growth medium based on cane blackstrap molasses, we compared ethanol production by two strains of Saccharomyces cerevisiae that were immobilized in polyurethane foam cubes in a fluidized bed fermenter. One strain (NCYC 1119) was adhesive and extremely flocculent, whilst the other strain was not adhesive and only weakly flocculent. The strong flocs of NCYC 1119 caused blockage of the bed, so that stable operation could not be achieved beyond 15 days. Nevertheless, it was able to produce $40 \mathrm{~g} \mathrm{~L}^{-1}$ ethanol at a rate up to $16 \mathrm{~g} \mathrm{~L}^{-1} \mathrm{~h}^{-1}$ ( $\mathrm{D}=0.4$ $\mathrm{h}^{-1}$ ), although this production period was limited to $192 \mathrm{~h}$. In contrast, the non-adhesive strain was only capable of producing $28 \mathrm{~g} \mathrm{~L}^{-1}$ ethanol at a rate of $11 \mathrm{~g} \mathrm{~L}^{-1} \mathrm{~h}^{-1}$ at the same dilution rate, even though production continued for $576 \mathrm{~h}$. Despite the conversion of sugars to ethanol not being complete during these trials (up to $47 \mathrm{~g} \mathrm{~L}^{-1}$ was expected), it was clearly demonstrated that the productivity of the adhesive strain was higher than that of the non-adhesive one. However, further work is required to develop this process into a robust, industrial system. 
Corresponding author: m.dempsey@mmu.ac.uk Phone: +44 (0)161 2471139 Fax: +44 (0)161 2476325

\section{Natural Immobilisation of Microorganisms for Continuous Ethanol Production}

Keywords: bioethanol; fluidized bed; fluidised bed; molasses; transport fuel; 2003/30/EC; immobilized cell

\section{Introduction}

The market for fuel ethanol will increase dramatically in the near future because of EU [1] and other legislation to promote the use of biofuels for transport. Using renewable sources of energy will be a major contribution to reducing net $\mathrm{CO}_{2}$ emissions, thereby helping to meet obligations under the Kyoto Protocol. Furthermore, agricultural wastes can be turned into valuable products and reliance on fossil fuels is reduced. The work reported here is part of an EUfunded project: FERMATEC. This was a multi-centre, multi-disciplinary, industry-research collaboration to develop a fluidized-bed fermenter (FBF) for the continuous production of ethanol at a concentration of 58-60 $\mathrm{g} \mathrm{L}^{-1}$ and at a rate of $25 \mathrm{~g} \mathrm{~L}^{-1} \mathrm{~h}^{-1}$ for periods of up to 30 days.

Ethanol can be produced by fermentation of sugars from agricultural products or waste plant materials [2], although attention must be paid to the overall economics and energy consumption of whichever system is chosen [3]. Using Saccharomyces yeasts in traditional batch fermentations for distilled ethanol production; productivity is limited to only $1.8-2.3 \mathrm{~g} \mathrm{~L}^{-1} \mathrm{~h}^{-1}$, which is uneconomic for biofuel production. Although continuous fermentation can increase this rate, even higher rates can be achieved if cell retention is also employed. This is the Brazil- 
ian solution, where continuous centrifuges are used to recycle biomass from the spent broth. However, centrifugation is expensive, in terms of both capital and running costs.

General strategies for cell retention include separation from the product stream followed by recycle to the fermenter or immobilization within the fermenter. Separation of cells from the product stream can be achieved using gravity- [4] or centrifuge- [5] assisted sedimentation or membrane separation [6] and recycle, or immobilization within the fermenter. Separation and recycle requires additional equipment and energy consumption and is therefore less suitable for the manufacture of marginal-cost products such as renewable fuels. In contrast, immobilization of cells does not require cell separation and recycle.

Immobilization methods can be artificial, having to rely on incorporation into a polymer gel [7] or natural, relying on the innate properties of microbes to become entrapped in biomass support particles [8] or attached to solid supports, such as coke [9]. The main problems with artificial immobilization are the requirement for a separate unit operation to manufacture the immobilized cell particles, which adds additional costs; and the fact that cells immobilized in this way have a shorter half-life, that is the entrapped cells eventually lose activity or die. For this reason, we used natural immobilization (entrapment and attachment), which presents the problem of finding suitably flocculent or adhesive organisms. Selection of microbes for attachment involves screening for adhesion to suitable supports and then screening for biofilm formation on support particles in e.g. an FBF.

Retention of cells not only results in a much higher biomass concentration compared to suspension cultures but it can also uncouple the dilution rate (D) from biomass wash-out, which typically occurs when $\mathrm{D}>0.8 \mu_{\max }$ if cells are not retained or recycled. It has previously been shown that a FBF for ethanol production from glucose by naturally-immobilized Zymomonas mobilis could be operated with $\mathrm{D}>11 \mu_{\max }[10]$. Because the volumetric productivity $\left(\mathrm{r}_{\mathrm{p}}\right)$ of this system was about 10-times higher than $\mu_{\max }$ at the ethanol concentration being produced [11], 
this is evidence that there was a low degree of diffusional limitation within the Zymomonas biofilm. In contrast, experimental work with flocculent yeast in a diffusion cell has shown that the rate of glucose diffusion was only $17 \%$ compared to the rate in pure water [12]. However, the diffusion rate in a fluidized bed is not the only controlling factor; external mass transfer in these systems is also important, and influenced strongly by the degree of bed expansion [13]. Natural immobilization of living cells and fluidized bed operation therefore presents several advantages over other types of immobilization, especially those methods involving incorporation into polymer gels.

\section{Materials and Methods}

\subsection{Screening for adhesion and biofilm formation}

Screening was carried out at $30^{\circ} \mathrm{C}$ and at natural $\mathrm{pH}(4.5-5.0)$ in fermenters with a height to diameter aspect ratio of about 10:1. Two strains of Saccharomyces cerevisiae, one flocculent (NCYC 1119, National Collection of Yeast Cultures, UK), and the other a non-flocculent yeast used for sparkling wine production were used. Three kinds of support were tested: 0.7-1.0 mm particles of glassy coke [14], made from bituminous coal; 1.0-1.4 mm particles of a light, ex-

panded clay aggregate in small spherical granules, Leca ${ }^{\circledR}$ [15]; and a reticulated (interconnecting pores) commercial type polyurethane foam (hand-cut into $4 \mathrm{~mm}$ cubes). The flocculent strain was also tested without support.

\subsection{Growth media}


The experiments on biofilm formation on coke used two growth media: one based on glucose (100 g L $\mathrm{L}^{-1}$ glucose (Cerestar, Manchester, UK), $5 \mathrm{~g} \mathrm{~L}^{-1}$ yeast extract powder (BioSpringer, London, $\mathrm{UK})$ and $1 \mathrm{~g} \mathrm{~L}^{-1}\left(\mathrm{NH}_{4}\right)_{2} \mathrm{SO}_{4}, \mathrm{BDH}$, Poole, $\left.\mathrm{UK}\right)$ and the other based on blackstrap cane molasses (Tate and Lyle, London, UK) diluted to $100 \mathrm{~g} \mathrm{~L}^{-1}$ sugars and $\left.1 \mathrm{~g} \mathrm{~L}^{-1}\left(\mathrm{NH}_{4}\right)_{2} \mathrm{SO}_{4}\right)$ ). Fluidisation of coke was achieved with an upward, superficial flow velocity of the growth medium equal to $1 \mathrm{~cm} \mathrm{~s}^{-1}$. In the adhesion tests on Leca ${ }^{\circledR}$ and polyurethane foam, the molassesbased medium (RAR, Porto, Portugal) had $100 \mathrm{~g} \mathrm{~L}^{-1}$ sugars and $\left.2 \mathrm{~g} \mathrm{~L}^{-1}\left(\mathrm{NH}_{4}\right)_{2} \mathrm{SO}_{4}\right)$. Fermenters for screening adhesion to coke were made from Quickfit process glassware (Corning, Stoke, UK) glass columns with a diameter to height aspect ratio of about 1:10, and were similar to those used by Dempsey, Black and Atkinson [10].

\subsection{Measurement of immobilized biomass}

Biofilm formation on coke was measured by the increase in static bed height, following bed settlement once the fluidizing pump had been switched off. This technique could not be used with molasses, because the medium was too dark to see through. Therefore, a different technique was used with Leca ${ }^{\circledR}$, where the attached biomass was quantified by the difference in dry weight after a sample dried at $105^{\circ} \mathrm{C}$ was ignited in an oven for 2 hours at $550^{\circ} \mathrm{C}$, to burn off the biomass. This technique could not be used for coke as it can burn at this temperature. None of these procedures could be used with the polyurethane foam but the transparent fermenter walls allowed observations of yeast growth in the foam cubes and of any increase in density so that they no longer floated but sank. 


\subsection{Bioreactor design}

Two reactors with different sizes and geometries were built to carry out the continuous fermentations. One (R1) was built using two Perspex ${ }^{\circledR}$ tubes in order to provide a jacket, for temperature control, through which circulated water from a water bath (3 in Fig. 1). Reactor (R1, Fig.1) had a volume of $1.0 \mathrm{~L}$, the inner tube diameter was $5.4 \mathrm{~cm}$, and the height/diameter ratio was 10 . The design of the second reactor R2, where the Perspex ${ }^{\circledR}$ tube has a diameter of $5.4 \mathrm{~cm}$, was different as it had an expansion zone at the top (diameter of $14 \mathrm{~cm}$ ), in stainless steel (grade 316), to allow for biomass retention in experiments carried out without support. In this reactor, temperature control was achieved by means of an external tubular heat exchanger, also in 316 stainless steel (4 in Fig. 2), through which flowed the recirculation stream. In this reactor (R2) the liquid level was controlled by the height of the discharge tube (3 in Fig. 2).

In the experiments carried out in these bioreactors, the polyurethane foam cubes were used as the support for natural immobilization of the $S$. cerevisiae strains. Prior to fermentation, the previously autoclaved foam cubes occupied $2 / 3$ of the height of the Perspex ${ }^{\circledR}$ tubes, which allowed for bed expansion due to both fluidization and biomass accumulation during the experiment. The reactors and tubes were sterilized with sodium hypochlorite solution (10\% v:v) and rinsed with sterilized water prior to operation. The gas outlets at the top of the reactors were protected with sterile cotton wool filters, to reduce the risk of contaminating microbes gaining entry. Peristaltic pumps were used to pump in growth medium and to recirculate culture fluid within the fermenter and effect bed expansion and particle fluidization.

Inocula were prepared by growing the yeast in Erlenmeyer flasks, in a synthetic medium consisting of malt extract ( $3 \mathrm{~g}$, from Sigma), yeast extract ( $3 \mathrm{~g}$, from Fluka), peptone from animal proteins (5 g, from Fluka), technical grade glucose (10 g, from Drogaria Moura, Porto, 
Portugal) and water (1L). The inocula were incubated for about 48 hours at $30^{\circ} \mathrm{C}$ and $120 \mathrm{rpm}$ in an orbital shaker.

Continuous culture fermentations were conducted using an autoclaved (80-120 minutes, depending on volume, at $\left.120^{\circ} \mathrm{C}\right)$ cane molasses based medium $\left(100 \mathrm{~g} \mathrm{~L}^{-1}\right.$ fermentable sugars), supplemented with $\left(\mathrm{NH}_{4}\right)_{2} \mathrm{SO}_{4}\left(2 \mathrm{~g} \mathrm{~L}^{-1}\right.$, from Sigma). The fermentation was started by adding $100 \mathrm{~mL}$ of inoculum to the reactors filled with sterile cane molasses medium. The bioreactors were run batch-wise for $48 \mathrm{~h}$, to establish the biomass prior to starting continuous culture operation. The fermentations were carried out at $30^{\circ} \mathrm{C}$. In both experiments the $\mathrm{pH}$ was not controlled, as only a narrow range of variation was recorded (4.4-4.6). In the experiment carried out in $\mathrm{R} 1$, the flocculent NCYC 1119 was used and in the first run the dilution rate was $0.4 \mathrm{~h}^{-1}$. Later in the experiment this was raised to 0.6 and $0.8 \mathrm{~h}^{-1}$. A narrower range of dilution rates $(0.2$ and $0.4 \mathrm{~h}^{-1}$ ) was used in the fermentation carried out in the $5 \mathrm{~L}$ reactor with the non flocculent strain.

\subsection{Analytical methods}

In the continuous fermentation with NCYC 1119, ethanol was measured by distillation according to the Portuguese Standard NP-2143, using a DENIS volumetric alcoholmeter, class II F80 01 851. During the experiment carried out in R2, analyses for sugars and ethanol were made periodically by HPLC. To remove biomass, the samples were centrifuged immediately after collection to sediment the biomass, then the supernatant was filtered through $0.2 \mu \mathrm{m}$ pore size membrane filter (Acrodisc syringe filters, $0.2 \mu \mathrm{m}$ Supor membrane, Pall, UK) and frozen for later analysis. The HPLC equipment used an RI detector (Knauer model K 301). The oven 
was set at $85^{\circ} \mathrm{C}$ and a PL Hi-Plex Ca $8 \mu \mathrm{m}$ column was used. Water was used for elution, at a

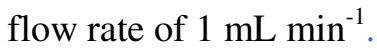

\section{Results and Discussion}

Attachment to or within each support material was demonstrated in all experiments, although its extent depended on the strain and the source of fermentable sugar used. Despite some operational problems faced when using molasses-based growth medium, most experiments were conducted with it, as it is a significantly cheaper source of fermentable sugars. Although this made for practical difficulties, we felt that it was necessary in order that volumetric productivity $\left(r_{p}\right)$ was measured under industrially-relevant conditions.

\subsection{Natural immobilization to coke}

The flocculent yeast (NCYC 1119) formed good biofilms on coke when grown on a glucose based medium in an upflow fluidized bed. The biomass-colonised coke can be clearly seen in Fig. 3 and consequent biofilm growth caused the bed to expand by approximately $100 \%$ during the experiment. When grown on the glucose-based medium, S. cerevisiae NCYC 1119 attached to the coke and formed extensive biofilms, completely embedding the coke particles. This process has also been demonstrated with other strains of S. cerevisiae grown on a glucosebased medium (data not shown), as well as with Zymomonas mobilis [10]. However, when NCYC 1119 was grown on the molasses-based medium, attachment was poorer and biofilm formation not so extensive. Because the molasses-based medium is so dark in colour, it was not possible to record biofilm formation photographically. Unfortunately, in the larger reactors (R1 
and R2), fluidization of coke was not achieved because the available pumps did not have a high enough flow rate.

\subsection{Natural immobilization to Leca $^{\circledR}$}

Leca ${ }^{\circledR}$ was tested with the non flocculent strain of $S$. cerevisiae and with NCYC 1119 , using the molasses medium. Although the attached biomass reached $27.5 \mathrm{~g} \mathrm{~kg}_{\mathrm{Leca}^{-}}{ }^{-1}$ for the non flocculent strain and $63.9 \mathrm{~g} \mathrm{~kg}_{\mathrm{Leca}^{-}}{ }^{-1}$ for NCYC 1119, this support was found to be unsuitable because the carrier trapped $\mathrm{CO}_{2}$ internally and became buoyant, with about $30 \%$ being carried off in the upflowing liquid. This material will therefore not make a good biomass support for industrial use.

\subsection{Support-free performance}

NCYC 1119 was also tested without support, making use of its cells' ability to adhere to each other (flocculation), as in a tower fermenter [16]. Although the results were promising at a dilution rate of $0.2 \mathrm{~h}^{-1}$ in reactors $\mathrm{R} 1$ and $\mathrm{R} 2\left(\mathrm{r}_{\mathrm{p}}=9 \mathrm{~g} \mathrm{~L}^{-1} \mathrm{~h}^{-1}\right.$ in both), when the dilution rate was increased neither reactor was able to retain the biomass. This was in contrast to the seven months stable operation reported by Jones et al. [16] for their flocculent mutant and implies that our expansion zone (at the top of R2) was less effective for biomass retention than their settler.

Nevertheless biomass washout was also a consequence of the variable size of the flocs, which normally ranged from 2-5 mm but would spontaneously break into smaller flocs that were easily washed out. This phenomenon of disaggregation might be explained by an essential nutrient that became limited inside the cell aggregate and caused deflocculation [17]. However, 
this was unlikely to have been a carbon or nitrogen source, as shortage of either of these nutrients normally causes brewing strains to become flocculent [18].

As we were unable to repeat the process stability with NCYC 1119 reported by Jones et al. [16] for their mutant, it implies that either the strain or bioreactor design is critical to success with the tower fermenter concept.

\subsection{Immobilization in reticulated foam}

The reticulated structure of the polyurethane foam enabled adherence as well as entrapment of biomass. Therefore, when using molasses-based growth medium it proved to be a good support material, irrespective of whether the strain could flocculate strongly. Therefore, reticulated foam seems like an ideal biomass support material, as proposed originally by Atkinson et al. [8]. Nevertheless, in the early stages of fermentation, while biomass content was low, the density of our support caused clogging problems. The foams had to be confined in order to avoid support entrainment in the effluent stream. This was achieved by introducing two orifice baffles at the bottom and close to the top section of the Perspex ${ }^{\circledR}$ tubes in reactors R1 and R2.

Once operating in continuous culture mode at $D=0.4 \mathrm{~h}^{-1}$, it took 3-4 days for $r_{p}$ to reach steady-state in the $1 \mathrm{~L}$ reactor, using NCYC 1119 immobilized on polyurethane foam (Fig 4). For about 8 days, an average ethanol concentration of $40 \mathrm{~g} \mathrm{~L}^{-1}$ was achieved, when $\mathrm{r}_{\mathrm{p}}=16 \mathrm{~g} \mathrm{~L}^{-1}$ $\mathrm{h}^{-1}$. To increase $r_{p}$ further, D was raised to $0.6 \mathrm{~h}^{-1}$, which resulted in a decrease in ethanol concentration to $37 \mathrm{~g} \mathrm{~L}^{-1}$ but an increase in $\mathrm{r}_{\mathrm{p}}$ to $22 \mathrm{~g} \mathrm{~L}^{-1} \mathrm{~h}^{-1}$. A similar pattern of productivity increase but ethanol concentration decrease with increasing dilution rate was observed when $S$. cerevisiae were immobilized on porous microcarriers [19].

It was not practical to measure the biomass immobilized on the polyurethane foam but the clear acrylic fermenter walls allowed observation of the biomass building up in the system, 
which was operated in upflow. Operation at $\mathrm{D}=0.6 \mathrm{~h}^{-1}$ lasted for 4 days, before $\mathrm{D}$ was increased to $0.8 \mathrm{~h}^{-1}$. As biomass built up in the foams, they too became aggregated, which blocked the flow of medium and stopped operation after two days at the highest D. During this brief period, $\mathrm{r}_{\mathrm{p}}$ reached almost $33 \mathrm{~g} \mathrm{~L}^{-1} \mathrm{~h}^{-1}$. These results compare well to those of Bu'lock et al. [20], who also used a highly flocculent strain of $S$. cerevisiae but without support. Although the results achieved with the highly flocculent yeast (NCYC 1119) were promising, operation with this strain immobilized on foam beyond 15 days was not possible at this scale of operation because the amount of trapped yeast caused blocking of the columnar bioreactor. Therefore, to try to avoid the clogging problem, the non-flocculent yeast was used with the same sugar concentration but in a larger reactor $(5 \mathrm{~L})$.

Polyurethane foams have a low initial density, which increases as biomass accumulates inside. In the experiment with the non-flocculent yeast, downflow was used and a recirculation stream $\left(\mathrm{Q}=10 \mathrm{Q}_{\text {inlet }}\right)$ was introduced to help expand the bed. This strategy enabled us to carry out continuous operation for 24 days (Fig. 5). Continuous tests in the $5 \mathrm{~L}$ fermenter started at D $=0.2 \mathrm{~h}^{-1}$ for 13 days, when $\mathrm{r}_{\mathrm{p}}=7 \mathrm{~g} \mathrm{~L}^{-1} \mathrm{~h}^{-1}$. A higher dilution rate $\left(0.4 \mathrm{~h}^{-1}\right)$ was used, to increase $\mathrm{r}_{\mathrm{p}}$. Although this was achieved $\left(11 \mathrm{~g} \mathrm{~L}^{-1} \mathrm{~h}^{-1}\right)$ it was not as good as the $16 \mathrm{gL}^{-1} \mathrm{~h}^{-1}$ obtained with NCYC 1119. In these two runs, the mean yield of both was close to $70 \%$ of theoretical, which indicates that ethanol production could be improved by process optimisation.

Problems experienced with the pumps forced us to stop the experiment when it had been running for 24 days. Visual observation allows us to report that the biomass accumulated on the support was less than in the previous experiment; therefore it was not a limiting parameter. Although ethanol productivity was lower, these are encouraging result bearing in mind that in industrial practice long term operation is required [3]. 


\section{Conclusions}

This study has demonstrated the advantage of immobilized cell systems for dramatically increasing volumetric productivity. Despite the use of molasses as the sugar source, which is known to be harder to ferment than e.g. glucose, $\mathrm{r}_{\mathrm{p}}$ was raised to over $22 \mathrm{~g} \mathrm{~L}^{-1} \mathrm{~h}^{-1}$ for a sustained period. This is very close to a primary aim of the FERMATEC project $\left(25 \mathrm{~g} \mathrm{~L}^{-1} \mathrm{~h}^{-1}\right)$ and gives us confidence that we shall be able to develop a first-generation immobilized cell fermenter to help establish a sustainable fuel ethanol industry in the EU.

\section{Acknowledgements}

This work was part of the FERMATEC Project, ENK5-CT-2002-30029, funded by the EU DG XII. 
Figure 1 Schematic diagram of the $1 \mathrm{~L}$ fermenter $(\mathrm{R} 1)$. The dimensions are: height $=55 \mathrm{~cm}$, Inside diameter $=5.4 \mathrm{~cm}$. $[1-$ Peristaltic pump, $2-$ Recirculation stream peristaltic pump, $3-$ Water jacket inlet and outlet.]

Figure 2 Apparatus layout for the $5 \mathrm{~L}$ fermenter (R2). The dimensions are: height $90 \mathrm{~cm}$; top section diameter $=14 . \mathrm{cm}$, Lower section inside diameter $=5.4 \mathrm{~cm} .[1$ and $2-$ Peristaltic pumps, 3 - Outlet tube, 4 - Heat exchanger.]

Figure 3 Natural immobilization of Saccharomyces cerevisiae NCYC 1119 on coke in an upflow fluidized bed (upward velocity $=1 \mathrm{~cm} \mathrm{~s}^{-1} ; 100 \mathrm{~g} \mathrm{~L}^{-1}$ glucose, $5 \mathrm{~g} \mathrm{~L}^{-1}$ yeast extract powder and $\left.\left.1 \mathrm{~g} \mathrm{~L}^{-1}\left(\mathrm{NH}_{4}\right)_{2} \mathrm{SO}_{4}\right)\right)$. Note the dense packing of the biomass-colonised coke, which equated to approximately $100 \%$ bed expansion over the static state.

Figure 4 Volumetric productivity of ethanol in a $1 \mathrm{~L}$ reactor using flocculent Saccharomyces cerevisiae NCYC 1119 naturally-immobilized in $4 \mathrm{~mm}$ polyurethane foam cubes during continuous fermentation of $100 \mathrm{~g} \mathrm{~L}^{-1}$ sugars (cane molasses $+\left(\mathrm{NH}_{4}\right)_{2} \mathrm{SO}_{4} 2 \mathrm{~g} \mathrm{~L}^{-1}$ ).

Figure 5 Volumetric productivity of ethanol in a $5 \mathrm{~L}$ reactor using non-flocculent Saccharomyces cerevisiae naturally-immobilized in $4 \mathrm{~mm}$ polyurethane foam cubes during continuous fermentation of $100 \mathrm{~g} \mathrm{~L}^{-1}$ sugars (cane molasses $+\left(\mathrm{NH}_{4}\right)_{2} \mathrm{SO}_{4} 2 \mathrm{~g} \mathrm{~L}^{-1}$ ). 
Baptista et al., Figure 1

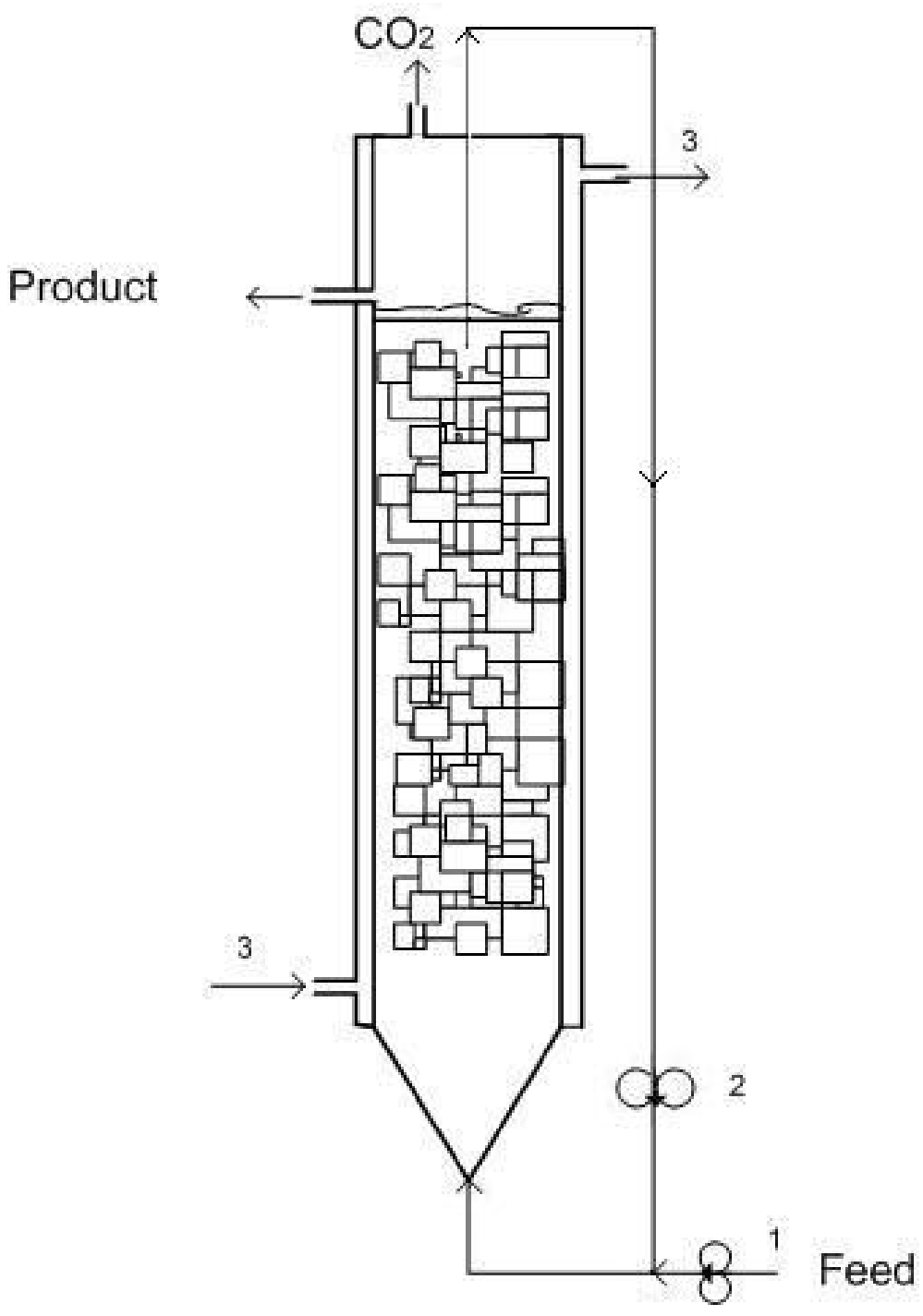


Baptista et al., Figure 2

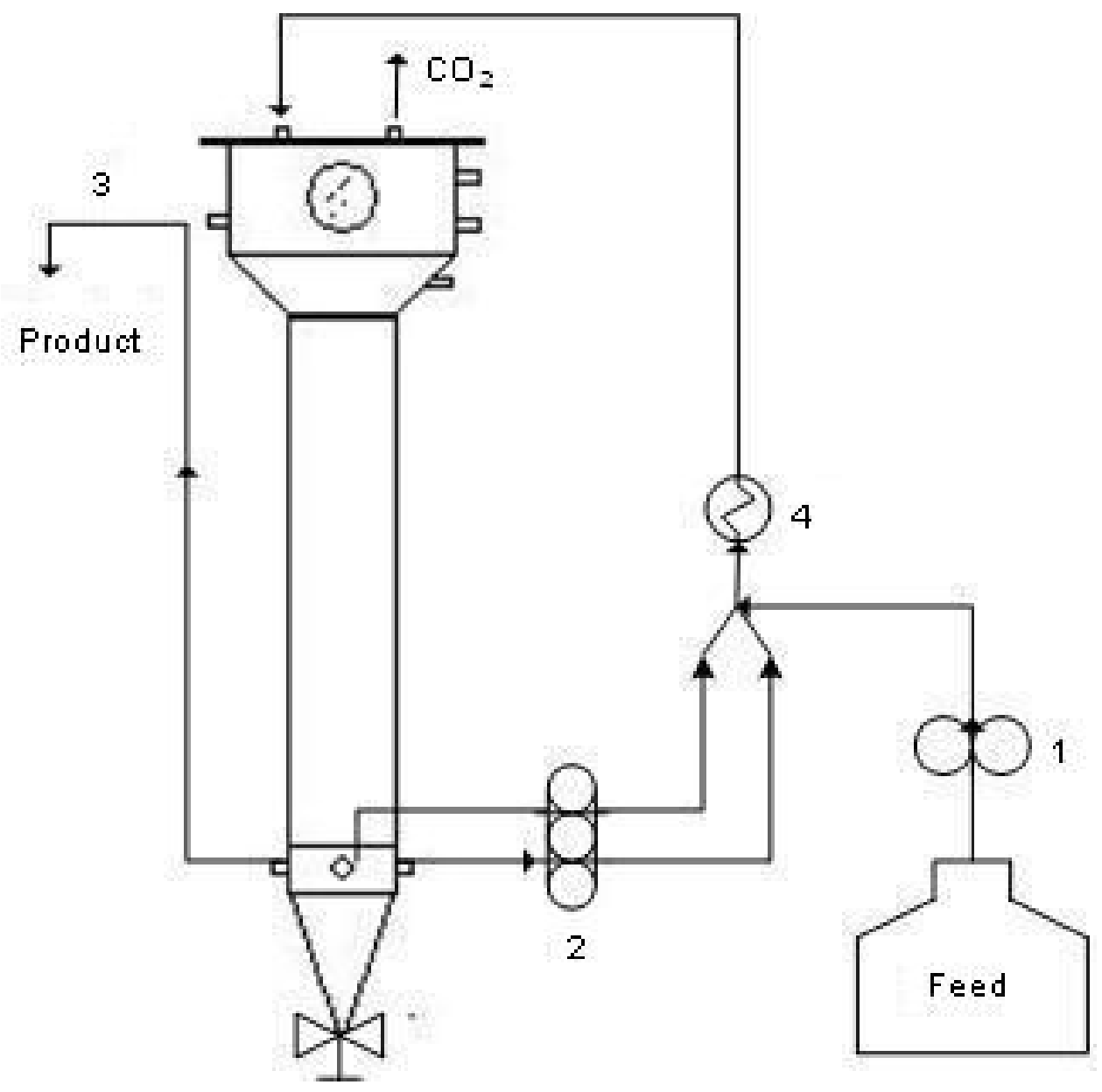


Baptista et al., Figure 3

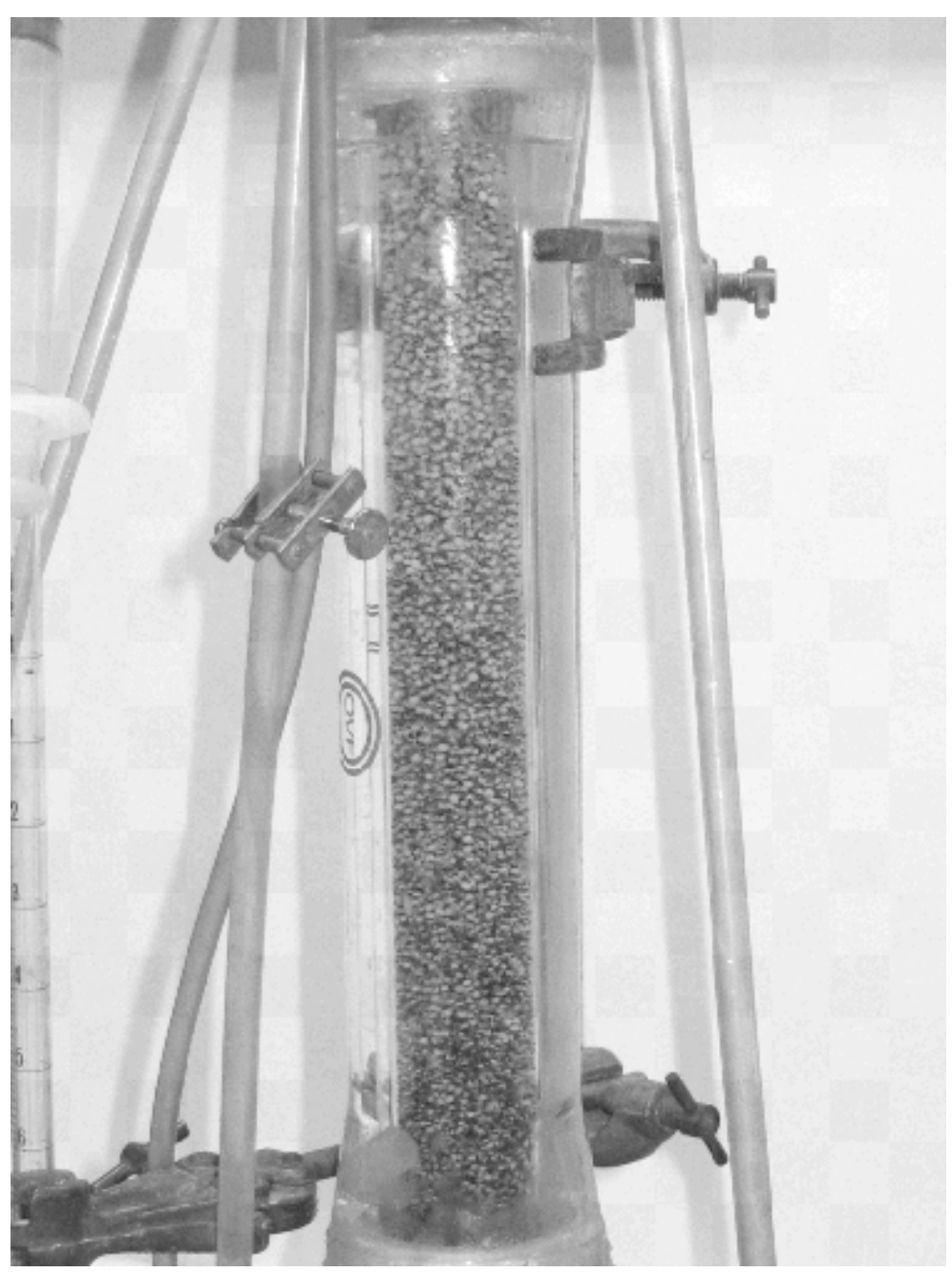


Baptista et al., Figure 4

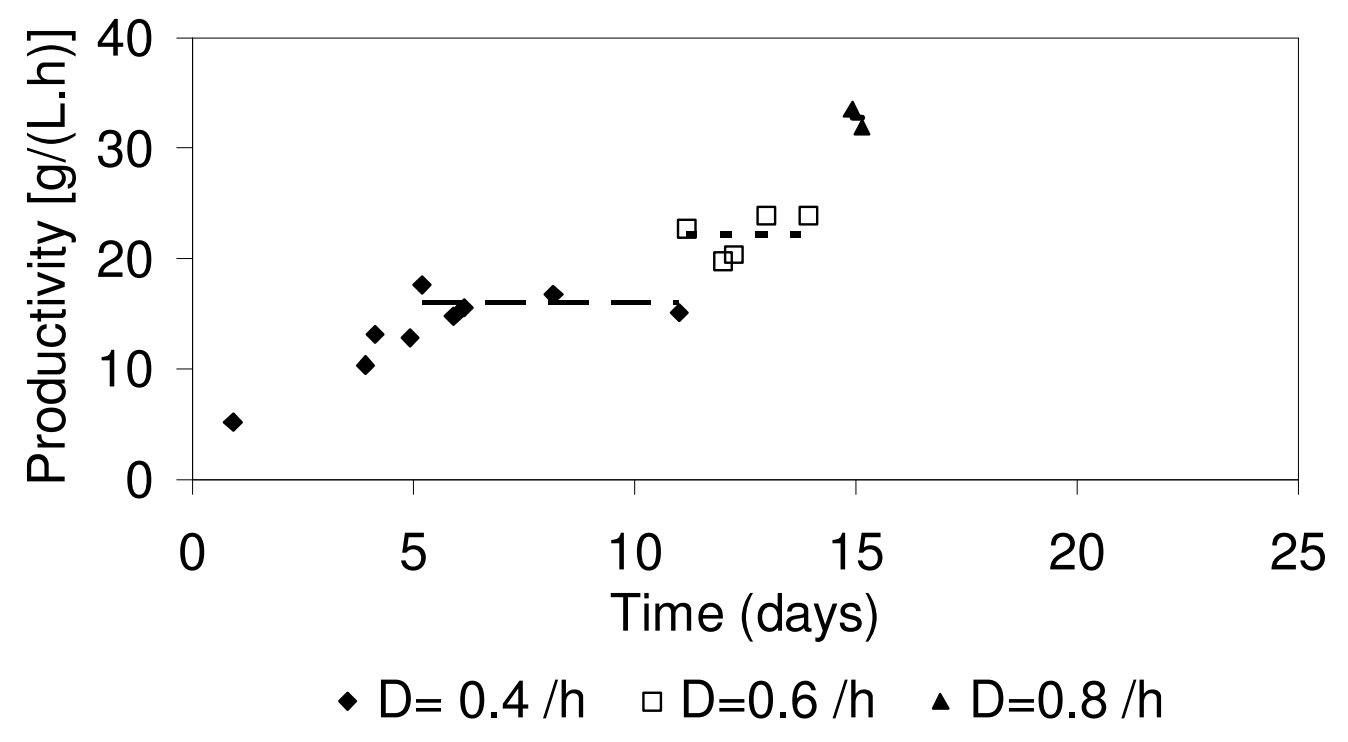


Baptista et al., Figure 5

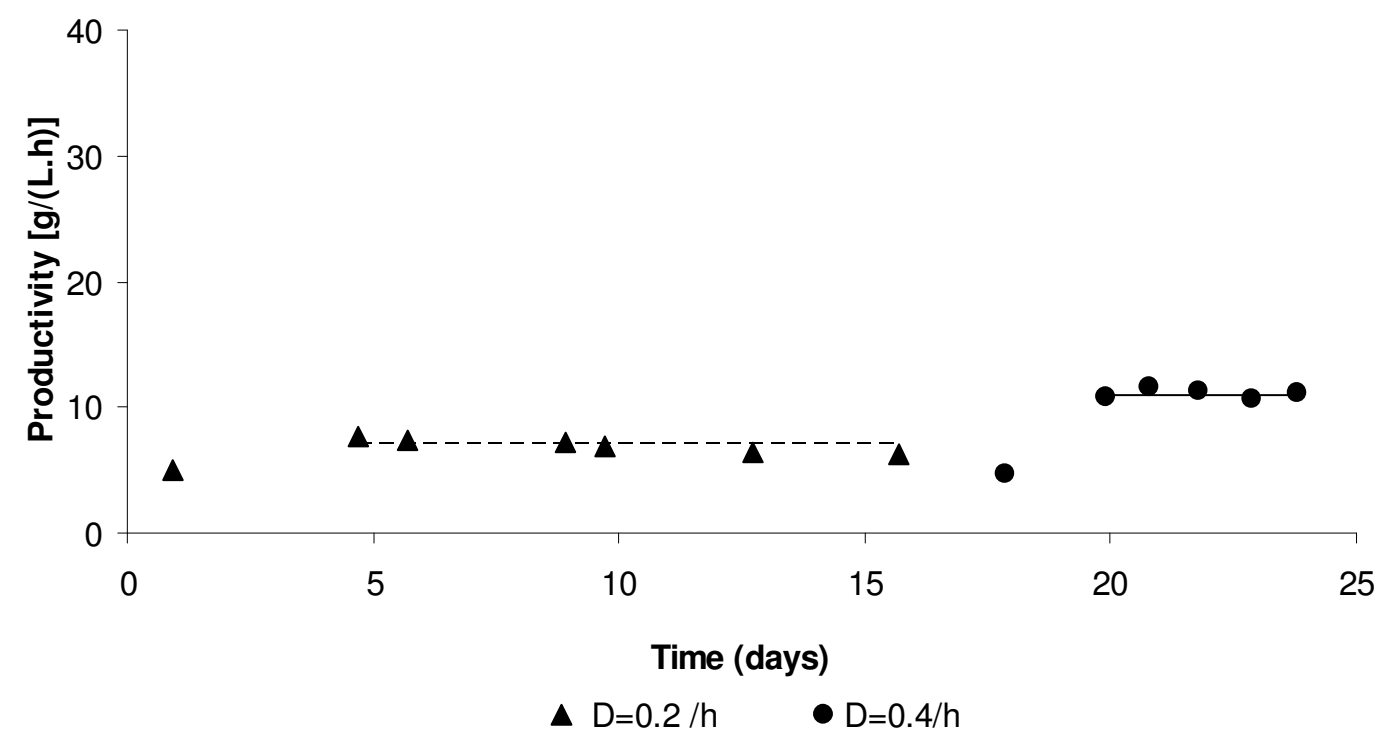




\section{References}

1. 2003/30/EC, D.

2. Bothast, R.J. and B.C. Saha, Ethanol production from agricultural biomass substrates, in Advances In Applied Microbiology, Vol 44. 1997, Academic Press Inc: San Diego. p. 261-286.

3. Ulgiati, S., A comprehensive energy and economic assessment of biofuels: When "green" is not enough. Critical Reviews In Plant Sciences, 2001. 20(1): p. 71-106.

4. Davis, R.H., C.Y. Lee, B.C. Batt, and D.S. Kompala, Cell Separations Using Differential Sedimentation In Inclined Settlers. Acs Symposium Series, 1991. 464: p. 113-127.

5. Hoeks, F., H. Kulla, and H.P. Meyer, Continuous Cell-Recycle Process For L-Carnitine Production - Performance, Engineering And Downstream Processing Aspects Compared With Discontinuous-Processes. Journal Of Biotechnology, 1992. 22(1-2): p. 117-127.

6. Chang, H.N., I.K. Yoo, and B.S. Kim, High-Density Cell-Culture By Membrane-Based Cell Recycle. Biotechnology Advances, 1994. 12(3): p. 467-487.

7. Willaert, R.G. and G.V. Baron, Gel entrapment and micro-encapsulation: Methods, applications and engineering principles. Reviews In Chemical Engineering, 1996. 12(1-2): p. 5-205.

8. Atkinson, B., G.M. Black, and A. Pinches, Process Intensification Using Cell Support Systems. Process Biochemistry, 1980. 15(4): p. 24-\&.

9. Dempsey, M.J., Biofilms and fluidized bed fermentation. International Biodeterioration \& Biodegradation, 1994. 34(3-4): p. 237-244.

10. Dempsey, M.J., G.M. Black, and B. Atkinson. Natural Immobilization of Adhesive Microorganisms in a Solid Support, Fluidized Bed Fermenter for the Continuous Production of Ethanol. in Process Engineering Aspects of Immobilised Cell Systems. 1984. UMIST, Manchester, UK: Inst. Chemical Engineers, Rugby 1986.

11. Jobses, I.M.L. and J.A. Roels, The Inhibition Of The Maximum Specific Growth And Fermentation Rate Of Zymomonas-Mobilis By Ethanol. Biotechnology And Bioengineering, 1986. 28(4): p. $554-563$. 
12. Vicente, A.A., M. Dluhy, E.C. Ferreira, M. Mota, and J.A. Teixeira, Mass transfer properties of glucose and O-2 in Saccharomyces cerevisiae flocs. Biochemical Engineering Journal, 1998. 2(1): p. 35-43.

13. Ruggeri, B., G. Caire, V. Specchia, G. Sassi, F. Bosco, and A. Gianetto, Determination Of Optimal Biofilm Activity In A Biological Fluidized-Bed (Bfb) Reactor. Water Science And Technology, 1994. 29(10-11): p. 347-351.

14. Dempsey, M.J., US6572773 Nitrification process. $2003 \mathrm{~b}$.

15. Leca, www.leca.pt.

16. Jones, S.T., R.A. Korus, W. Admassu, and R.C. Heimsch, Ethanol fermentation in a continuous tower fermentor. Biotechnology and Bioengineering, 1984. 26(7): p. 742-747.

17. Stratford, M., Yeast Flocculation - A New Perspective. Advances In Microbial Physiology, 1992. 33: p. 1-71.

18. Sampermans, S., J. Mortier, and E.V. Soares, Flocculation onset in Saccharomyces cerevisiae: the role of nutrients. Journal Of Applied Microbiology, 2005. 98(2): p. 525-531.

19. Nguyen, V.T. and W.K. Shieh, Continuous Ethanol Fermentation Using Immobilized Yeast In A Fluidized-Bed Reactor. Journal Of Chemical Technology And Biotechnology, 1992. 55(4): p. 339-346.

20. Bulock, J.D., D.M. Comberbach, and C. Ghommidh, A Study Of Continuous Ethanol-Production Using A Highly Flocculant Yeast In The Gas Lift Tower Fermenter. Chemical Engineering Journal And The Biochemical Engineering Journal, 1984. 29(1): p. B9-B24. 